\title{
Erratum to: System-Level Use of Contextual Information
}

\author{
Alan N. Steinberg and Galina L. Rogova
}

\section{Erratum to:}

Chapter 7 in: L. Snidaro et al. (eds.), Context-Enhanced Information Fusion, Advances in Computer Vision and Pattern Recognition, DOI 10.1007/978-3-319-28971-7_7

The book was inadvertently published with an incorrect order of authors in Chap. 7, the correct order should be "Alan N. Steinberg and Galina L. Rogova" rather than "Galina L. Rogova and Alan N. Steinberg".

The updated original online version for this chapter can be found at DOI 10.1007/978-3-319-28971-7_7

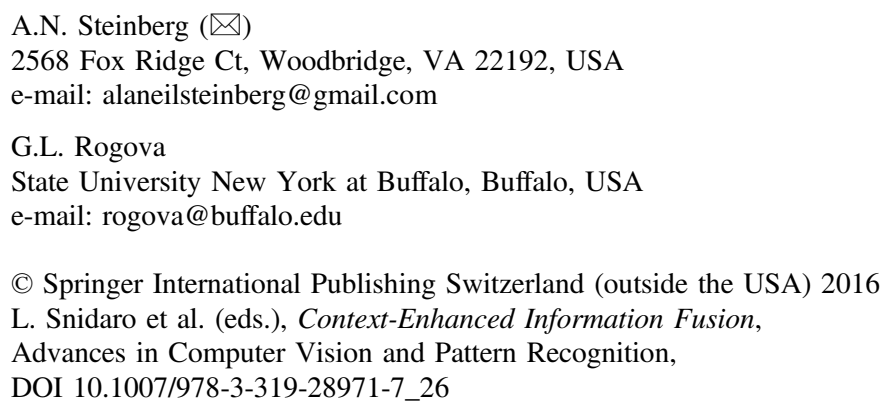

